\title{
Removal of chlorophenols from aqueous solutions by sorption onto walnut, pistachio and hazelnut shells
}

\author{
Krzysztof Kuśmierek*, Andrzej Świątkowski \\ Military University of Technology, Institute of Chemistry, gen. Sylwester Kaliski 2, 00-908 Warsaw, Poland \\ "Corresponding author: e-mail: kkusmierek@wat.edu.pl
}

\begin{abstract}
The efficiency of walnut, pistachio and hazelnut shells to remove three monochlorophenols (2-CP, 3-CP and 4-CP) from aqueous solutions has been investigated. To describe the kinetic data pseudo-first and pseudo-second order models were used. The kinetics data were fitted better into the pseudo-second order model with the coefficient of determination values greater than 0.99 . The $\mathrm{k}_{2}$ values increased in the order 4-CP $<3$-CP $<2$-CP. Sorption was also analyzed as a function of solution concentration at equilibrium. The experimental data received were found to be well described by the Freundlich isotherm equation. Effectiveness of chlorophenols removal from water on the walnut, pistachio and hazelnut shells was comparable. Individual differences in sorption of monochlorophenols were also negligible.
\end{abstract}

Keywords: nut shells, walnut, pistachio, hazelnut, chlorophenols, sorption.

\section{INTRODUCTION}

Chlorophenols (CPs) are organic compounds of cyclic aromatics formed by replacing hydrogen atoms in phenol molecule by chlorine atoms. They can be introduced into the water, soil and air from various sources such as wood and fibers preservatives, production and use of pesticides ${ }^{1,2}$ or as possible by-products of drinking water disinfection ${ }^{3}$. Because of the long persistence and high toxicity of chlorophenols their use is prohibited or restricted in many countries ${ }^{4}$.

Different methods for removal of chlorophenols from water, including biodegradation ${ }^{5,6}$, oxidation by Advanced Oxidation Processes (AOPs) ${ }^{7-10}$ and adsorption, especially on activated carbons ${ }^{11-15}$ are used. In particular, for its high efficiency, and simplicity of operation, adsorption on activated carbon has proven to be one of the most attractive and effective methods for removal of phenolic compounds from water. However, their use is associated with several disadvantages. Regeneration of spent activated carbons produces additional effluents, and moreover, is expensive and impractical on a large scale ${ }^{16-18}$. Recently, numerous approaches have been studied for the development of cheaper and effective sorbents as an alternative to replace costly activated carbon ${ }^{18-27}$. They should be cheap, easily available and disposable without regeneration. Many non-conventional low-cost sorbents that are available in large quantities, including natural and biological materials ${ }^{16-23,27}$ (e.g. zeolites, clay, chitin, chitosan, peat, yeasts, fungi or bacterial biomass, wood, barley and rice husk), and waste materials from industry and agriculture ${ }^{16-18,20}$ (e.g. fly ash, red mud, sludges), have been proposed by several authors. Nut shells waste, which presents serious disposal problems to the environment, is also available as a low-cost by-product from food industries. The use of nut shells as low-cost adsorbents is very advantageous from a technological point of view, because, in contrast to other adsorbents, there is no problem with their disposal. After use nut shells can be utilized in waste incineration plants or may be a high calorific fuel for industry (e.g. electric power stations, cement factories). Removal of chlorophenols was investigated only on coconut shells ${ }^{24,25}$. Hazelnut shells were applied for water removal of dyes ${ }^{28,29}$ and metal ions ${ }^{30,31}$, whereas walnut shells were used as sorbents for removal of sulfamethoxazole $e^{32}$ and copper(II $)^{30}$, chromium(VI) ${ }^{\mathbf{3 1}}$, lead(II $)^{\mathbf{3 3}}$ and cadmium(II) $)^{\mathbf{3 4}}$ ions.

The aim of the present study is to investigate and describe kinetics and equilibria of sorption of monochlorinated phenols (2-, 3-, and 4-chlorophenol) on walnut, hazelnut and pistachio shells from aqueous solutions.

\section{MATERIAL AND METHODS}

\section{Reagents and sorbents}

2-chlorophenol, >99\% (2-CP), 3-chlorophenol, 98\% (3-CP), and 4-chlorophenol, >99\% (4-CP) were from Sigma (St Louis, MO, USA). HPLC-grade acetonitrile, acetic acid, hydrochloric acid, sodium hydroxide and sodium chloride were received from POCH (Gliwice, Poland). As sorbents walnut (Juglans regia), pistachio (Pistacia vera) and hazelnut (Corylus avellana) shells were chosen. The crushed nut shells were sieved through two sieves $-2.0 \mathrm{~mm}$ sieve (No. 10) and $1.0 \mathrm{~mm}$ sieve (No. 18). Only the middle fraction was used in experiments - the average size of the shells ranged from 1.0 to 2.0 $\mathrm{mm}$. Then the mean diameter of the resulting particles was assumed as 1.5 millimeters. Before their use, all the sorbents were washed thoroughly with deionized water and oven dried at $130^{\circ} \mathrm{C}$ to constant weight.

The point of zero charge of the nut shells was determined by the $\mathrm{pH}$ drift method described by Ferro-García et al. ${ }^{35}$ To determine the $\mathrm{pH}_{\mathrm{PZC}}, 1.0 \mathrm{~g}$ of nut shells was added to Erlenmeyer flasks containing $50 \mathrm{~mL}$ of 0.01 $\mathrm{mol} / \mathrm{L} \mathrm{NaCl}$. The $\mathrm{pH}$ within each flask was adjusted to values ranging from 2 to 12 by adding either $0.1 \mathrm{~mol} / \mathrm{L}$ $\mathrm{NaOH}$ or $0.1 \mathrm{~mol} / \mathrm{L} \mathrm{HCl}$. Then, the flasks were shaken for $24 \mathrm{~h}$, and the final $\mathrm{pH}$ of the solution was measured. The final $\mathrm{pH}$ was plotted against the initial $\mathrm{pH}$ and the intersection point of the obtained curve was taken as the point of zero charge, $\mathrm{pH}_{\mathrm{PZC}}$.

The specific surface area of nut shells was determined by a Gemini 2360 surface area analyzer (Micromeritics, Norcross, GA, USA). Scanning electron microscopy analysis (SEM, LEO 1430VP, Electron Microscopy Ltd., 
Cambridge, England) was carried out for the nut shells to study the surface morphology. A micro-analytical SEM-EDS method (EDS analysis system Quantax 200, Bruker-AXS Microanalysis, Berlin, Germany, integrated with SEM) was applied to the quantitative chemical compositions of sorbents surface. These studies were conducted in Laboratory of Instrumental Analysis, Nicolaus Copernicus University, Toruń, Poland.

\section{Sorption procedures}

The effect of sorbent dose was studied by varying the dosages of nut shells from 0.25 to $1.5 \mathrm{~g}$, in $40 \mathrm{~mL}$ of solution, at constant initial chlorophenol concentration of $0.2 \mathrm{mmol} / \mathrm{L}$. The experiments were conducted only for walnuts and 2-chlorophenol, because we assumed that the other sorbents and other monochlorophenols will behave similarly.

The effect of $\mathrm{pH}$ on the 2-CP, 3-CP and 4-CP removal was studied by varying the initial $\mathrm{pH}$ of the solutions from $\mathrm{pH} 2$ to 12 . The $\mathrm{pH}$ was adjusted using $0.1 \mathrm{~mol} / \mathrm{L}$ $\mathrm{HCl}$ and $0.1 \mathrm{~mol} / \mathrm{L} \mathrm{NaOH}$. The monochlorophenols initial concentration was fixed at $0.25 \mathrm{mmol} / \mathrm{L}$, with nut shells dosage of $1.0 \mathrm{~g}$ per $40 \mathrm{~mL}$ of the solution.

Sorption experiments were carried out in a batch mode with following procedure. For each time $1.0 \mathrm{~g}$ of walnut, pistachio or hazelnut shells and $40 \mathrm{~mL}$ of monochlorophenols solutions were mixed in an Erlenmeyer flask, which were then shaken. After mixing, solutions were filtered and analyzed by high-performance liquid chromatography with UV detection.

The kinetic studies were conducted for initial concentration of aqueous solution $0.25 \mathrm{mmol} / \mathrm{L}$ at temperature of $25^{\circ} \mathrm{C}$. The amount of sorption at time $\mathrm{t}, \mathrm{q}_{\mathrm{t}}(\mathrm{mmol} / \mathrm{g})$, was calculated by the following equation:

$\mathrm{q}_{\mathrm{t}}=\mathrm{V} \frac{\mathrm{C}_{0}-\mathrm{C}_{\mathrm{t}}}{\mathrm{m}}$

where: $\mathrm{C}_{0}$ and $\mathrm{C}_{\mathrm{t}}$ are the initial concentration and chlorophenol concentration at time $\mathrm{t}(\mathrm{mmol} / \mathrm{L}), \mathrm{V}$ is the volume of the solution (L) and $\mathrm{m}$ is the mass of the sorbent $(\mathrm{g})$.

In sorption isotherm studies, solutions with different initial concentrations of $2-\mathrm{CP}, 3-\mathrm{CP}$ or $4-\mathrm{CP}(0.05-0.5$ $\mathrm{mmol} / \mathrm{L})$ were prepared. The equilibrium time was set as 4 hours and mass of all sorbents was $1.0 \mathrm{~g}$. The uptake of the monochlorophenols at equilibrium, $\mathrm{q}_{\mathrm{e}}(\mathrm{mmol} / \mathrm{g})$, was calculated from equation (2):

$\mathrm{q}_{\mathrm{e}}=\mathrm{V} \frac{\mathrm{C}_{0}-\mathrm{C}_{\mathrm{e}}}{\mathrm{m}}$

where: $\mathrm{C}_{\mathrm{e}}$ is equilibrium concentration of chlorophenol (mmol/L) solution.

The final equilibrium concentrations of the chlorophenols in solutions were measured chromatographically.

\section{Analytical method}

For determination of 2-CP, 3-CP and 4-CP a high-performance liquid chromatography method with UV detection was used (Shimadzu LC-20, Kyoto, Japan). The chromatographic analyzes were carried out under isocratic conditions on a Phenomenex Luna C18, 4.6×150 mm, $3 \mu \mathrm{m}$ column (Torrance, CA, USA). The mobile phase consisted of acetonitrile and water adjusted to $\mathrm{pH} 3.0$ with acetic acid $(50 / 50, \mathrm{v} / \mathrm{v})$. The temperature was $40^{\circ} \mathrm{C}$, the flow rate $0.25 \mathrm{~mL} / \mathrm{min}$, and the detector wavelength was from 274 to $281 \mathrm{~nm}$.

\section{RESULTS AND DISCUSSION}

\section{Characterization of the sorbents}

Scanning electron micrographs of walnut, hazelnut and pistachio shells are presented in Figure 1. The elemental analysis data (Table 1) showed that the walnut and pistachio have similar compositions. Hazelnuts differ quite significantly. They have significantly less of nitrogen and aluminum, and additionally, have magnesium and calcium, which are not observed in the walnut and pistachio. The BET surface area of walnut, pistachio and hazelnut shells was $11.2,12.1$ and $9.8 \mathrm{~m}^{2} / \mathrm{g}$, respectively. In the literature there is no information about the $\mathrm{S}_{\mathrm{BET}}$ of the nut shells. According to the best of our knowledge, only Teixeira et al. ${ }^{32}$ reported the values for the walnut shells $\left(13.1 \pm 0.1 \mathrm{~m}^{2} / \mathrm{g}\right)$. The result obtained by us is lower. It

(a)

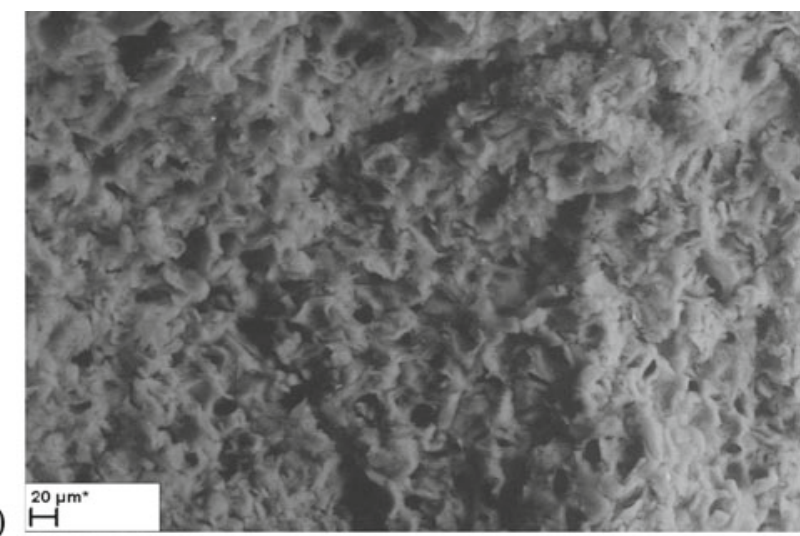

(b)

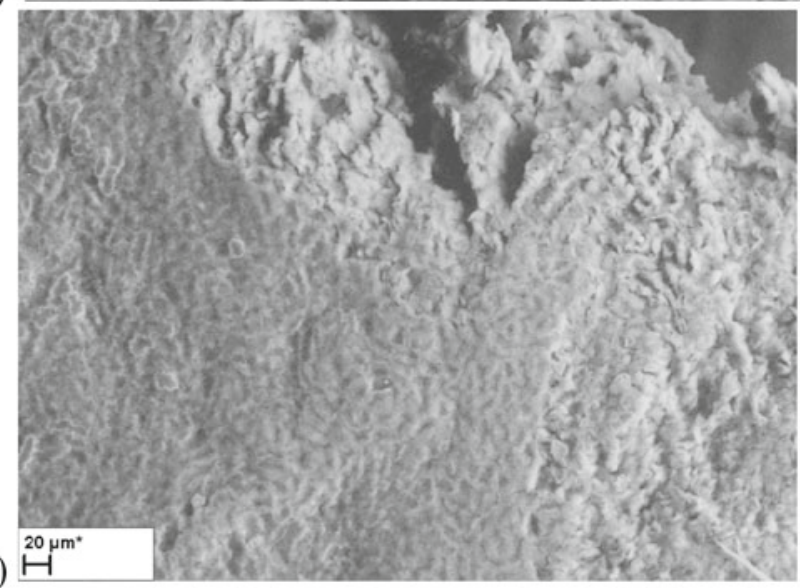

(c)

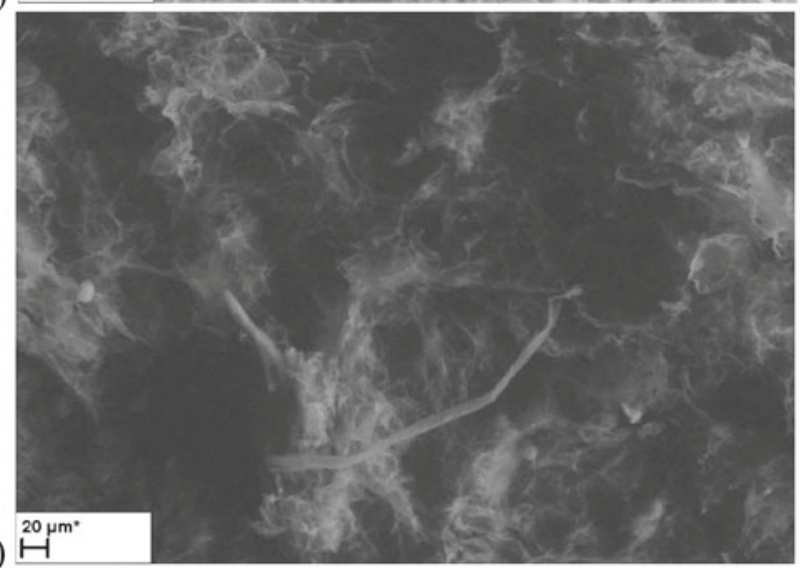

Figure 1. SEM images of (a) walnut (b) pistachio and (c) hazelnut shells 
Table 1. Elemental composition of all three sorbents from SEM-EDS

\begin{tabular}{|l|c|c|c|c|c|c|}
\hline \multirow{2}{*}{ Nut shells } & \multicolumn{5}{|c|}{ Mass percent [\%] } \\
\cline { 2 - 7 } & $\mathrm{O}$ & $\mathrm{C}$ & $\mathrm{N}$ & $\mathrm{Al}$ & $\mathrm{Ca}$ & $\mathrm{Mg}$ \\
\hline Walnut & 72.28 & 17.29 & 6.10 & 4.33 & - & - \\
\hline Pistachio & 71.35 & 17.91 & 6.59 & 4.15 & - & - \\
\hline Hazelnut & 73.82 & 18.34 & 3.21 & 2.58 & 1.54 & 0.50 \\
\hline
\end{tabular}

may be caused by some other measurement apparatus or a different sorbent fragmentation $\left(0.25-0.50 \mathrm{~mm}^{32} \mathrm{vs}\right.$. $1.0-2.0 \mathrm{~mm}$ in these studies).

The $\mathrm{pH}_{\mathrm{PZC}}$ values of walnut, pistachio and hazelnut shells are 4.6, 5.1 and 5.0, respectively, and are in general agreement with those obtained by other authors ${ }^{30-33}$.

\section{Effect of sorbent dose}

The effect of the sorbent dose was studied for five walnut shells amounts: $0.25,0.50,0.75,1.0$ and $1.50 \mathrm{~g}$. The results, presented in Figure 2, show that the sorption of 2-chlorophenol increases with increase in the amount of sorbent. The $\%$ of chlorophenol removed from aqueous solution after 4 hours increased from 3.9 to $13.5 \%$ when 0.25 and $1.50 \mathrm{~g}$ of walnut shells were used, respectively. The increase in chlorophenol sorption is possibly due to

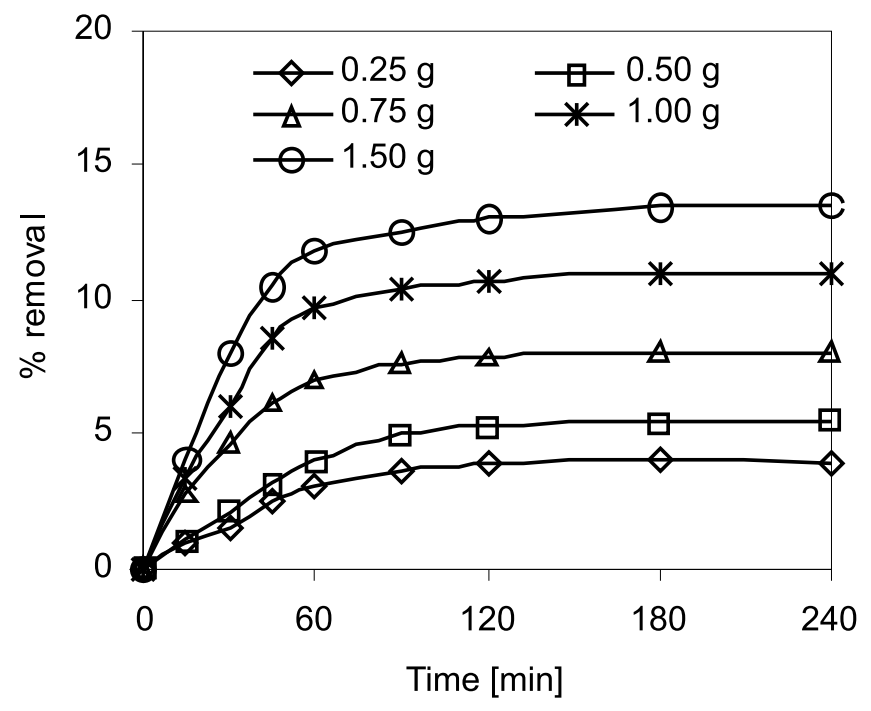

Figure 2. Efficacy of sorption of 2-chlorophenol on walnut shells

the increase availability of 2-CP binding sites resulting from an increase in sorbent dosage. A dose of $1.0 \mathrm{~g}$ of sorbent was considered for further sorption experiments.

\section{Effect of pH}

The effect of solution $\mathrm{pH}$ was studied in the range of 2 to 12 and the results are presented in Figure 3. As it is seen, the removal of chlorophenols was almost constant from $\mathrm{pH} 2$ to 4 and decreased significantly with further increase in $\mathrm{pH}$. For example, the amount of 4-CP adsorbed at equilibrium $\left(\mathrm{q}_{\mathrm{e}}\right)$ on walnut, pistachio and hazelnut shells decreases from 0.0019 to $0.0001 \mathrm{mmol} / \mathrm{g}$, from 0.0030 to $0.0003 \mathrm{mmol} / \mathrm{g}$ and from 0.0026 to 0.0002 $\mathrm{mmol} / \mathrm{L}$, respectively. It was suggested that the sorption is highly dependent on $\mathrm{pH}$ of the solution which affects the surface charge of the nut shells, and the degree of ionization and speciation of the monochlorophenols.

The $\mathrm{pK}_{\mathrm{a}}$ of 2-CP, 3-CP and 4-CP is 8.3-8.6, 8.8-9.1 and 9.1-9.4, respectively ${ }^{1}$. At lower $\mathrm{pH}$ values $\left(\mathrm{pH}<\mathrm{pK}_{\mathrm{a}}\right)$ chlorophenols are present as the neutral (protonated)
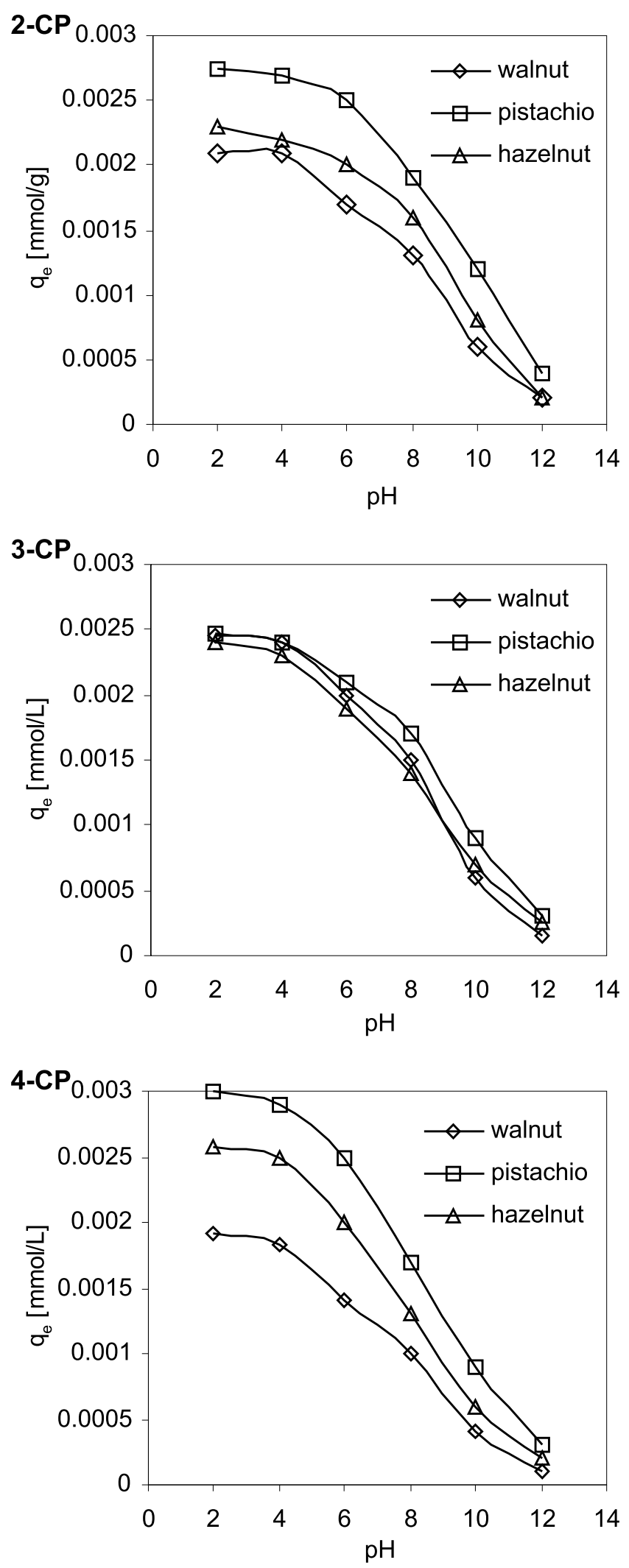

Figure 3. Effect of $\mathrm{pH}$ on the sorption amount of 2-CP, 3-CP and 4-CP on nut shells 
form, while at a higher $\mathrm{pH}\left(\mathrm{pH}>\mathrm{pK}_{\mathrm{a}}\right)$ they are deprotonated and exist as the negatively charged phenoxide ions. The $\mathrm{pH}_{\mathrm{PZC}}$ values of walnut, pistachio and hazelnut shells are 4.6, 5.1 and 5.0, respectively. The surface charge of the sorbents is positive when the solution $\mathrm{pH}$ is below the $\mathrm{pH}_{\mathrm{PZC}}$ value while it is negative at a $\mathrm{pH}$ over the $\mathrm{pH}_{\mathrm{PzC}}{ }^{36}$. As $\mathrm{pH}$ increases, the degree of dissociation of chlorophenol molecules becomes higher thereby making it more negatively charged. This leads to increased electrostatic repulsion or dispersion between the phenoxide ions and the nut shell surface and subsequently a decrease in chlorophenol uptake with increase in $\mathrm{pH}$ as was observed in the $\mathrm{pH}$ from 2 to 12 . The surface of walnut, pistachio and hazelnut shells is positively charged at $\mathrm{pH}$ below 4.6, 5.1 and 5.0, respectively, and negatively charged at $\mathrm{pH}$ above these values. Therefore, nut shells exhibit higher sorption potential for chlorophenols at lower $\mathrm{pH}$.

The results showed that the $\mathrm{pH}$ strongly influences the chlorophenols sorption onto nut shells, however, the behavior of all three chlorophenols is very similar on all sorbents investigated. These similarities are due to the similar nature of sorbates $\left(\mathrm{pK}_{\mathrm{a}}\right)$ and sorbents $\left(\mathrm{pH}_{\mathrm{PZC}}\right)$. Despite the fact that the $\mathrm{pH}$ significantly affect the sorption of chlorophenols on nut shells, all subsequent studies were carried out in distilled water $(\mathrm{pH}$ 6.5-7.0).

\section{Kinetic studies}

Figure 4 shows the sorption kinetics of all monochlorinated phenols on walnut, pistachio and hazelnut shells. It was observed, that the sorption equilibrium was achieved after approximately 2 hours for all the cases examined. The experimental results were described by the pseudo-first and pseudo-second order models equations. The pseudo-first-order rate equation ${ }^{37}$ is expressed as:

$\log \left(\mathrm{q}_{\mathrm{e}}-\mathrm{q}_{\mathrm{t}}\right)=\log \mathrm{q}_{\mathrm{e}}-\frac{\mathrm{k}_{1}}{2.303} \mathrm{t}$

where $\mathrm{q}_{\mathrm{e}}$ and $\mathrm{q}_{\mathrm{t}}$ are the amounts of sorption at equilibrium and at time $t$, respectively, and $\mathrm{k}_{1}$ is the pseudo-first order rate constant. Straight line plots of $\log \left(q_{e}-q_{t}\right)$ versus $\mathrm{t}$ were used to determine the rate constants $\mathrm{k}_{1}$, and correlation coefficients $\mathrm{R}^{2}$.

The pseudo-second-order rate equation ${ }^{\mathbf{3 8}}$ is given as:

$\frac{\mathrm{t}}{\mathrm{q}_{\mathrm{t}}}=\frac{1}{\mathrm{k}_{2} \mathrm{q}_{\mathrm{e}}{ }^{2}}+\frac{1}{\mathrm{q}_{\mathrm{e}}} \mathrm{t}$

where $\mathrm{q}_{\mathrm{e}}$ and $\mathrm{q}_{\mathrm{t}}$ are the amounts of sorption at equilibrium and at time $t$, respectively, and $\mathrm{k}_{2}$ is the pseudo-second order rate constant. The plot $\mathrm{t} / \mathrm{q}_{\mathrm{t}}$ against $\mathrm{t}$ should give a straight line if pseudo-second-order kinetics is
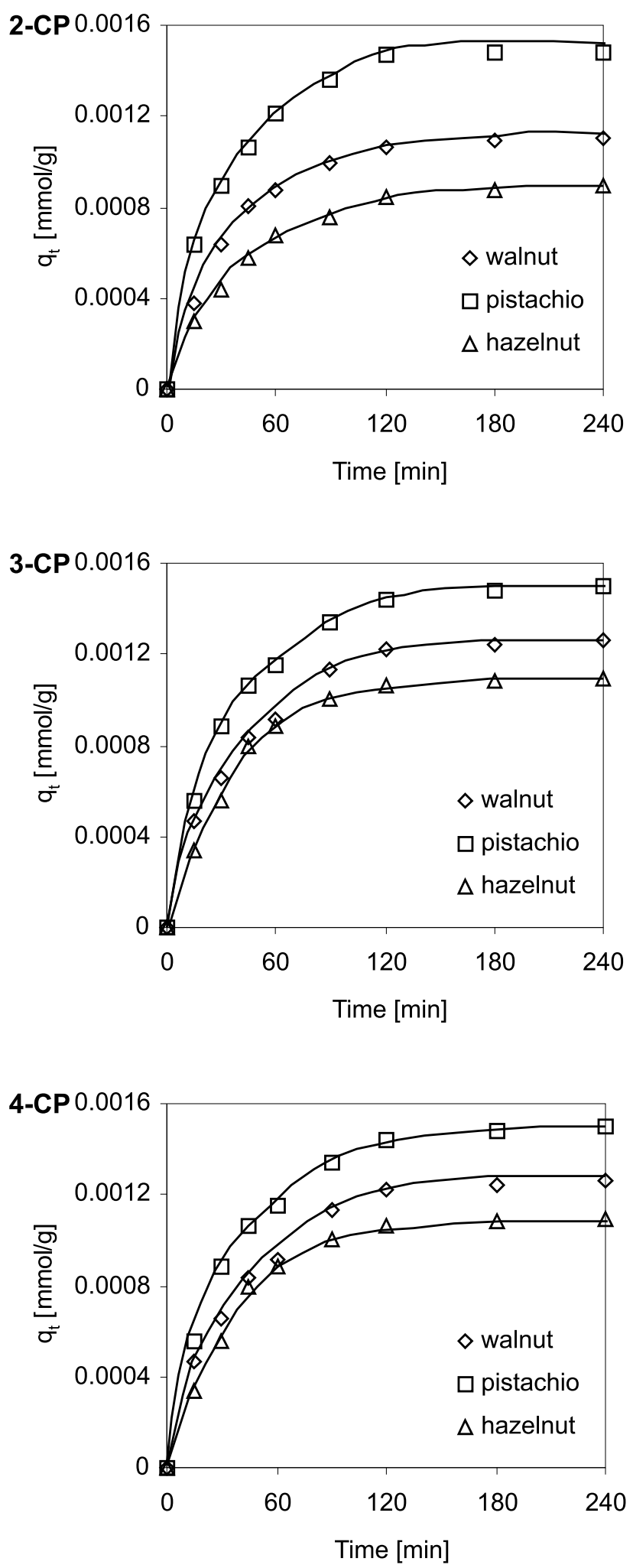

Figure 4. Sorption kinetics of chlorophenols on walnut, pistachio and hazelnut shells

Table 2. Pseudo-first and pseudo-second order rate constants for sorption of chlorophenols on nut shells

\begin{tabular}{|l|c|c|c|c|c|}
\hline \multirow{2}{*}{ Nut shells } & Compound & \multicolumn{2}{|c|}{ Pseudo-first order model } & \multicolumn{2}{|c|}{ Pseudo-second order model } \\
\cline { 2 - 6 } & & $\mathrm{k}_{1}[1 / \mathrm{min}]$ & $\mathrm{R}^{2}$ & $\mathrm{k}_{2}[\mathrm{~g} / \mathrm{mmol} \cdot \mathrm{min}]$ & $\mathrm{R}^{2}$ \\
\hline \multirow{3}{*}{ Walnut } & $2-\mathrm{CP}$ & 0.024 & 0.994 & 29.268 & 0.997 \\
& $3-\mathrm{CP}$ & 0.026 & 0.989 & 21.687 & 0.996 \\
\hline \multirow{3}{*}{ Pistachio } & $4-\mathrm{CP}$ & 0.022 & 0.995 & 26.888 & 0.991 \\
& $2-\mathrm{CP}$ & 0.035 & 0.951 & 22.034 & 0.997 \\
\hline \multirow{3}{*}{ Hazelnut } & 3-CP & 0.022 & 0.989 & 9.802 & 0.998 \\
& $4-\mathrm{CP}$ & 0.025 & 0.960 & 27.110 & 0.997 \\
& 2-CP & 0.023 & 0.993 & 25.684 & 0.992 \\
& 3-CP & 0.026 & 0.976 & 11.232 & 0.992 \\
\hline
\end{tabular}


applicable and $\mathrm{k}_{2}$ can be determined from the linear equation of the plot. The rate constants $\left(\mathrm{k}_{1}, \mathrm{k}_{2}\right)$ and correlation coefficients $\mathrm{R}^{2}$ of the both kinetic models are listed in Table 2.

In general, the pseudo-second order model fits the experimental data quite well with correlation coefficients better than 0.99 . These facts suggest that the sorption of chlorophenols by nut shells follows the pseudo-second order kinetic model. The 2-chlorophenol is sorbed more rapidly than 3-chlorophenol, and definitely faster than 4-chlorophenol. The $\mathrm{k}_{2}$ values follow the order of 2-CP $>3-\mathrm{CP}>4-\mathrm{CP}$. On the other hand, the type of sorbent does not significantly affect the rate of sorption of the individual compounds. The $\mathrm{k}_{2}$ values observed for walnut, pistachio and hazelnut shells are similar for the same chlorophenols. For example, the values of $\mathrm{k}_{2}$ calculated for 2-chlorophenol are 29.2, 26.9 and $27.1 \mathrm{~g} / \mathrm{mmol} \cdot \mathrm{min}$ for walnuts, pistachios and hazelnuts, respectively.

In order to investigate the mechanism of adsorption the intraparticle diffusion model (Weber-Morris model) ${ }^{\mathbf{3 9}}$ was also used. The Weber-Morris equation is described as:

$\mathrm{q}_{\mathrm{t}}=\mathrm{k}_{\mathrm{i}} \mathrm{t}^{1 / 2}+\mathrm{C}_{\mathrm{i}}$

where: $k_{i}$ is the intraparticle diffusion rate constant $\left(\mathrm{mmol} / \mathrm{g} \cdot \mathrm{min}^{-1 / 2}\right)$ and $\mathrm{C}_{\mathrm{i}}$ is the thickness of the boundary layer. The plots $q_{t}=f\left(t^{1 / 2}\right)$ for all chlorophenols onto walnut, pistachio and hazelnut shells are presented in Figure 5. If the plot passes through the origin, then the rate limiting process is only due to the intraparticle diffusion. Moreover, the plot $\mathrm{q}_{\mathrm{t}}$ versus $\mathrm{t}^{1 / 2}$ is linear when the intraparticle diffusion occurs ${ }^{40,41}$. As can be seen in the Figure 5 none of the lines passed through the origin. This suggests that the intraparticle diffusion was not the only rate-controlling step. The plots shown in Figure 5 were not linear over the whole time range, indicating that more than one process affected the adsorption. The first, sharper region is the instantaneous adsorption or external surface adsorption, whereas the second step correspond to the gradual adsorption stage, where intraparticle diffusion is the rate-limiting step.

\section{Equilibrium studies}

Figure 6 shows the sorption isotherms of 2-chlorophenol, 3-chlorophenol and 4-chlorophenol on walnut, pistachio and hazelnut shells (left column) and percentage removal of chlorophenols versus equilibrium concentration (right column). As can be seen the course of the isotherms is almost linear. According to the isotherms classification introduced by Giles et al. ${ }^{42}$, they can be classified into $\mathrm{C} 1$ isotherms. The $\mathrm{C}$ curves (linear curves) are given by solutes which penetrate into the solid more readily than does the solvent. A similar isotherm shape was observed for adsorption of water on wool ${ }^{42}$, disperse dyes on cellulose diacetate ${ }^{42}$, phenol on cellulose triacetate $^{42}$ or chlorophenols on peat ${ }^{27}$.

To test the fitting of the experimental data the Freundlich isotherm mode $\mathrm{l}^{43}$ was used. The Freundlich isotherm is given by equation (6):

$\mathrm{q}_{\mathrm{e}}=\mathrm{K}_{\mathrm{F}} \mathrm{C}_{\mathrm{e}}{ }^{1 / \mathrm{n}}$

which can be linearized to:

$\ln \mathrm{q}_{\mathrm{e}}=\ln \mathrm{K}_{\mathrm{F}}+\frac{1}{\mathrm{n}} \ln \mathrm{C}_{\mathrm{e}}$
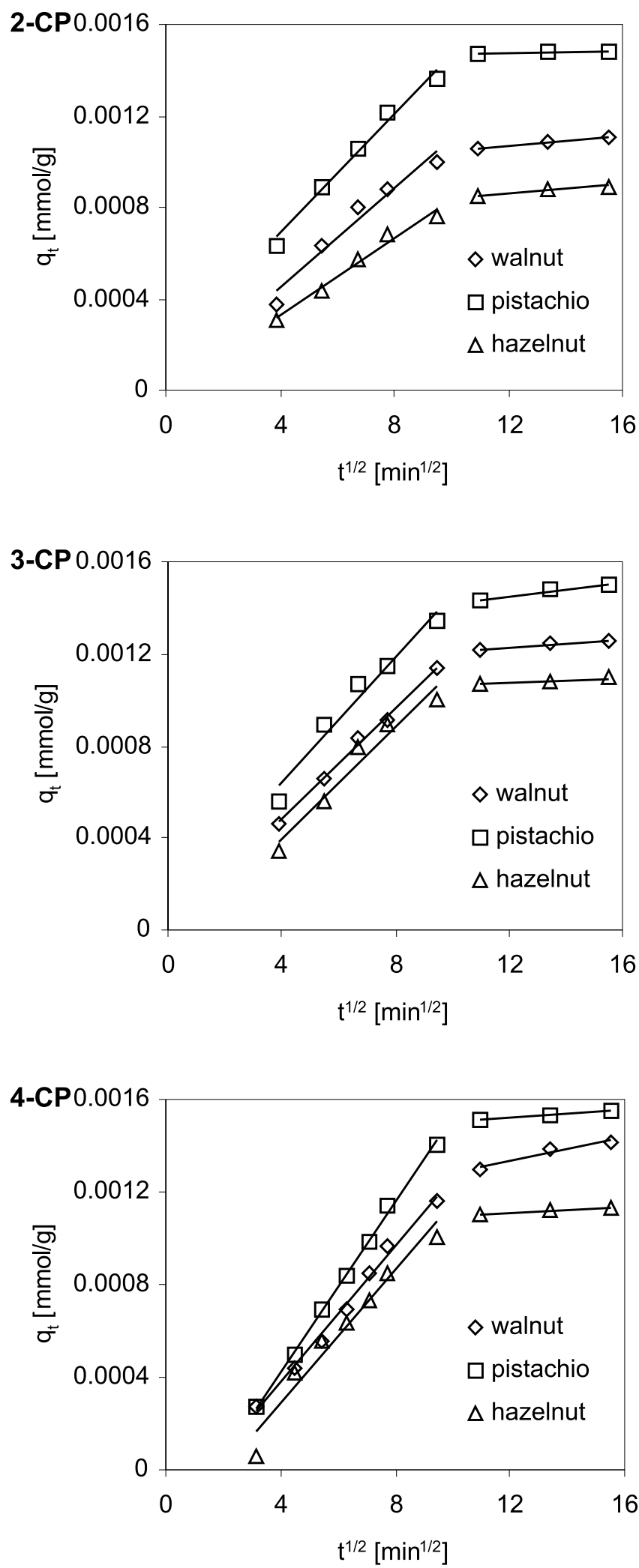

Figure 5. Intraparticle diffusion model for the sorption of 2-CP, 3-CP and 4-CP on nut shells

where: $\mathrm{K}_{\mathrm{F}}(\mathrm{mmol} / \mathrm{g}) \cdot(\mathrm{L} / \mathrm{mmol})^{1 / \mathrm{n}}$, and $\mathrm{n}$ are Freundlich equation constants which relate to sorption capacity and sorption intensity of the sorbent. These constants were calculated from the intercept and slope of $\ln \mathrm{q}_{\mathrm{e}}$ versus $\ln \mathrm{C}_{\mathrm{e}}$ plot and are listed in Table 3. The linear Freundlich isotherm plots of 2-CP, 3-CP and 4-CP are presented in Figure 7.

The linear regression correlation coefficient values show that the equilibrium data obtained for all chlorophenols were well represented by the Freundlich isotherm model 

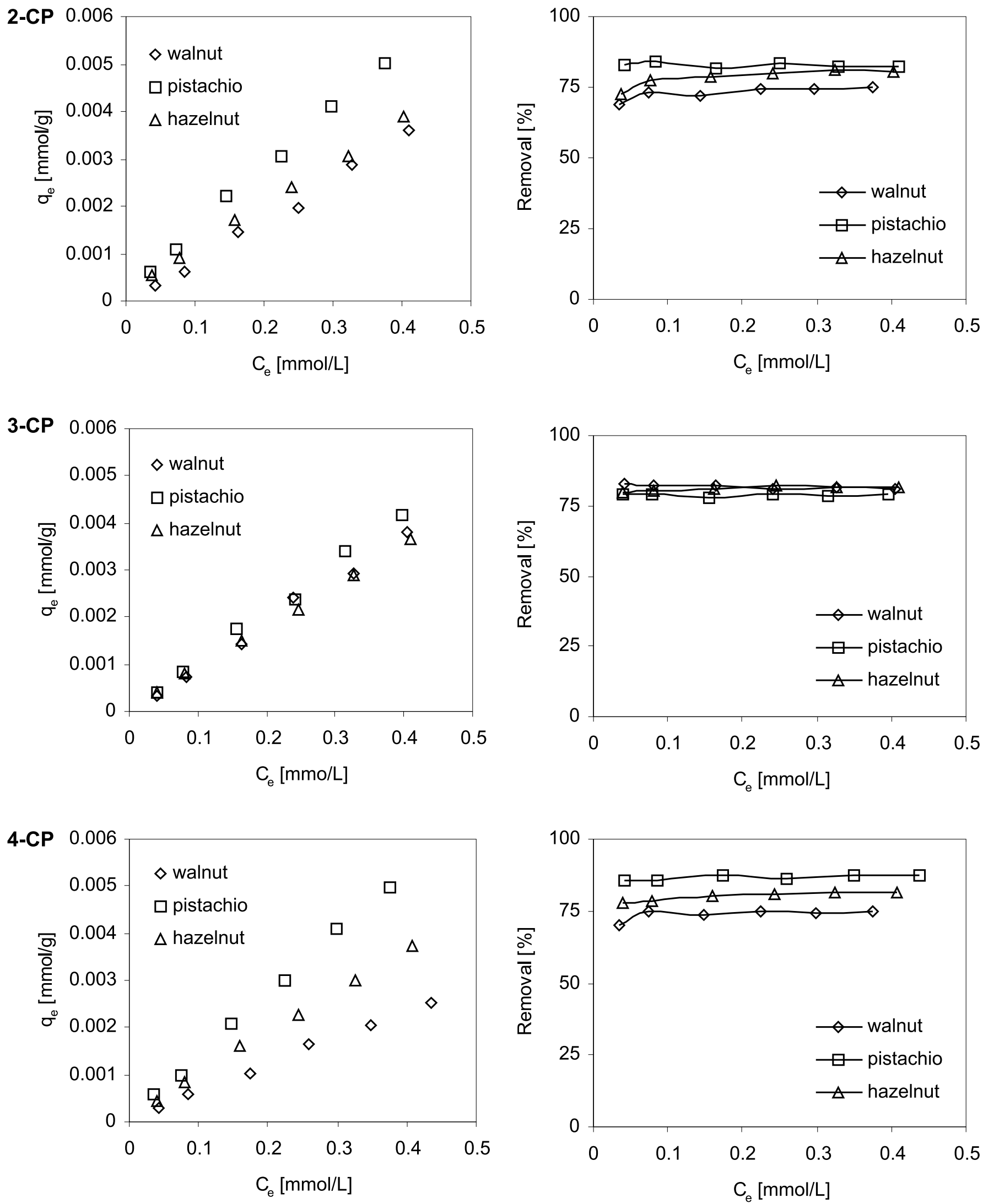

Figure 6. Sorption isotherms of 2-CP, 3-CP and 4-CP on nut shells (left column) and removal of chlorophenols by walnut, pistachio and hazelnut shells (right column)

$\left(\mathrm{R}^{2}>0.99\right)$. The results indicate that the best sorbent for the removal of chlorophenols from water are pistachio and then walnuts, and hazelnuts. However, the differences are very small. These observations also confirmed by plots of $\%$ removal vs equilibrium concentration (Fig. 6, right column). The \% removal of chlorophenols increases in the order hazelnuts $<$ walnuts $<$ pistachios. The results show also that there is no correlation between the ele- mental composition of the nut shells and their adsorption capacities. The $\mathrm{K}_{\mathrm{F}}$ values calculated for 2-chlorophenol were $0.009,0.012$ and $0.007(\mathrm{mmol} / \mathrm{g}) \cdot(\mathrm{L} / \mathrm{mmol})^{1 / n}$ for walnut, pistachio and hazelnut, respectively. The position of the chlorine atom in the molecule does not affect the monochlorophenol sorption. On the same nut shells sorption of 2-CP, 3-CP or 4-CP is at the same level. The $\mathrm{K}_{\mathrm{F}}$ values observed for 2-CP, 3-CP and 4-CP were 
Table 3. Freundlich isotherm model parameters for sorption of chlorophenols on nut shells

\begin{tabular}{|c|c|c|c|c|}
\hline \multirow[t]{2}{*}{ Nut shells } & \multirow[t]{2}{*}{ Compound } & \multicolumn{3}{|c|}{ Freundlich isotherm } \\
\hline & & $\mathrm{n}$ & $\mathrm{K}_{\mathrm{F}}$ & $\mathrm{R}^{2}$ \\
\hline \multirow{3}{*}{ Walnut } & $2-\mathrm{CP}$ & 0.966 & 0.009 & 0.995 \\
\hline & 3-CP & 0.951 & 0.009 & 0.997 \\
\hline & 4-CP & 1.073 & 0.008 & 0.998 \\
\hline \multirow{3}{*}{ Pistachio } & $2-\mathrm{CP}$ & 1.121 & 0.012 & 0.997 \\
\hline & 3-CP & 1.007 & 0.011 & 0.997 \\
\hline & 4-CP & 1.087 & 0.012 & 0.994 \\
\hline \multirow{3}{*}{ Hazelnut } & 2-CP & 1.231 & 0.007 & 0.997 \\
\hline & 3-CP & 1.078 & 0.007 & 0.999 \\
\hline & 4-CP & 1.107 & 0.008 & 0.999 \\
\hline
\end{tabular}
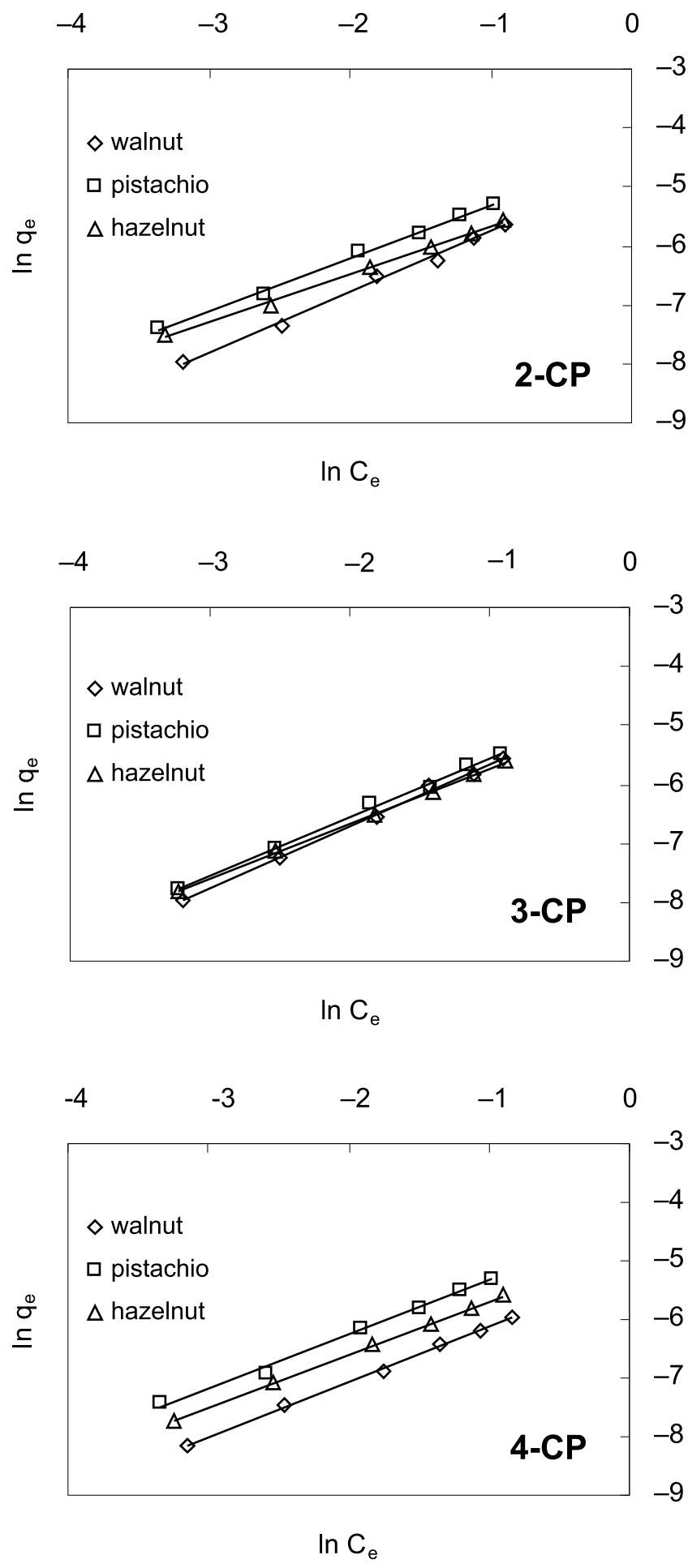

Figure 7. Linear Freundlich isotherm of 2-chlorophenol, 3-chlorophenol and 4-chlorophenol
0.009, 0.009 and 0.008 for walnut, $0.012,0.011$ and 0.012 for pistachio, and $0.007,0.007$ and $0.008(\mathrm{mmol} / \mathrm{g}) \cdot(\mathrm{L} /$ $\mathrm{mmol})^{1 / \mathrm{n}}$ for hazelnut shells.

\section{CONCLUSIONS}

The sorption experimental investigation indicated that the waste walnut, pistachio or hazelnut shells can be used as an alternative sorbents for the removal of chlorophenols from aqueous environment. The sorption kinetics revealed that the process followed the pseudo-second order kinetic model, whereas, the sorption equilibrium data were found to be well described by the Freundlich isotherm equation. The sorption equilibrium was achieved after approximately 2 hours - about three times faster than on activated carbon ${ }^{11,13,14}$.

To justify viability of nut shells as an effective sorbent for removal of chlorophenols from water, their sorption capacity of target pollutants needs to be compared with that of other sorbents. However, such a comparison is difficult and very relative due to different experimental conditions e.g. $\mathrm{pH}$, temperature, concentration range, wastewater composition, type of raw materials of the sorbent. The authors use different units (e.g. milligrams or millimoles) and various mathematical models describing the experimental data, which makes it more difficult to compare the results with each other. Therefore, sorption properties of the nut shells were compared with literature data obtained under similar experimental conditions. The Freundlich $\mathrm{K}_{\mathrm{F}}$ constant is an indicator of the adsorption capacity of the adsorbent. The $\mathrm{K}_{\mathrm{F}}$ values obtained for 4-chlorophenol sorption onto walnut, pistachio and hazelnut shells were $0.008,0.012$ and $0.008(\mathrm{mmol} / \mathrm{g}) \cdot(\mathrm{L} /$ $\mathrm{mmol})^{1 / \mathrm{n}}$, respectively. For comparison, the $\mathrm{K}_{\mathrm{F}}$ values for 4-CP were 0.025 on bentonite ${ }^{44}, 0.037$ on peat ${ }^{27}$, 0.118 on modified sewage sludge ${ }^{\mathbf{4 5}}, 0.139$ and 0.473 on short hydroxyl and carboxyl multi-walled carbon nanotubes $^{15}, 0.677$ on Vulcan XC 72 carbon black ${ }^{15}, 1.700$ on polymeric adsorbent ${ }^{46}, 2.138$ on Norit R3-ex activated carbon $^{15}$ and $2.267(\mathrm{mmol} / \mathrm{g}) \cdot(\mathrm{L} / \mathrm{mmol})^{1 / \mathrm{n}}$ on carbon fibers ${ }^{47}$. As can be seen, the sorption of $4-\mathrm{CP}$ on nut shells is slightly worse than in other low-cost sorbents. Compared to carbonaceous materials these differences are very significant. The sorption capacity of the nut shells for the chlorophenols removal is not excessive, especially in comparison to activated carbon, but these disadvantages can be compensated by their low cost and easy availability. 


\section{ACKNOWLEDGMENT}

We thank MSc Agata Dworakowska for technical assistance and Dr Grzegorz Trykowski for SEM-EDS measurements.

\section{LITERATURE CITED}

1. Czaplicka, M. (2004). Sources and transformations of chlorophenols in the natural environment. Sci. Total Environ. 322, 21-39. DOI: 10.1016/j.scitotenv.2003.09.015.

2. Armenante, P.M., Kafkewitz, D., Lewandowski, G.A. \& Jou, C.J. (1999). Anaerobic-aerobic treatment of halogenated phenolic compounds. Water Res. 33(3), 681-692. DOI: 10.1016/ S0043-1354(98)00255-3.

3. Ahlborg, U.G., Thunberg, T.M. \& Spencer, H.C. (1980). Chlorinated phenols: Occurrence, toxicity, metabolism, and environmental impact Crit. Rev. Toxicol. 7, 1-35.

4. EC Decision 2455/2001/EC of the European Parliament and the Council of November 20, 2001 establishing the list of priority substances in the field of water policy and amending Directive 2000/60/EC.

5. Bhatt, P., Kumar, M.S., Mudliar, S. \& Chakrabarti, T. (2007). Biodegradation of chlorinated compounds - A review. Crit. Rev. Environ. Sci. Technol. 37, 165-198. DOI: 10.1080/10643380600776130.

6. Olaniran, A.O. \& Igbinosa, E.O. (2011). Chlorophenols and other related derivatives of environmental concern: Properties, distribution and microbial degradation processes. Chemosphere 83, 1297-1306. DOI: 10.1016/j.chemosphere.2011.04.009.

7. Pera-Titus, M., Garcia-Molina, V., Banos, M., Jimenez, J. \& Esplugas, S. (2004). Degradation of chlorophenols by means of advanced oxidation processes: a general review. Appl. Catal. B-Environ. 47, 219-256. DOI: 10.1016/j.apcatb.2003.09.010.

8. Kucharska, M. \& Naumczyk, J. (2009). Degradation of selected chlorophenols by advanced oxidation processes. J. Environ. Prot. Eng. 35, 47-55.

9. Munoz, M., de Pedro, Z.M., Casas, J.A. \& Rodriguez, J.J. (2011). Assessment of the generation of chlorinated byproducts upon Fenton-like oxidation of chlorophenols at different conditions. J. Hazard. Mater. 190, 993-1000. DOI: 10.1016/j. jhazmat.2011.04.038.

10. Kuśmierek, K. \& Świątkowski, A. (2012). Removal of 4-chlorophenol from water by advanced oxidation processes based on hydrogen peroxide. Przem. Chem. 91(12), 2422-2424. [In polish].

11. Jung, M.W., Ahn, K.H., Lee, Y., Kim, K.P., Rhee, J.S., Park, J.T. \& Paeng, K.J. (2001). Adsorption characteristics of phenol and chlorophenols on granular activated carbons (GAC). Microchem. J. 70, 123-131. DOI: 10.1016/S0026-265X(01)00109-6. 12. Hamdaoui, O. \& Naffrechoux, E. (2007). Modeling of adsorption isotherms of phenol and chlorophenols onto granular activated carbon Part II. Models with more than two parameters. J. Hazard. Mater. 147, 401-411. DOI: 10.1016/j. jhazmat.2007.01.023.

13. Wu, F.C., Tseng, R.L., Huang, S.C. \& Juang, R.S. (2009). Characteristics of pseudo-second-order kinetic model for liquid-phase adsorption: A mini-review. Chem. Eng. J. 151, 1-9. DOI: 10.1016/j.cej.2009.02.024.

14. Kuśmierek, K., Sankowska, M. \& Świątkowski, A. (2014). Kinetic and equilibrium studies of simultaneous adsorption of monochlorophenols and chlorophenoxy herbicides on activated carbon, Desalin. Water Treat. 52, 178-183. DOI: 10.1080/19443994.2013.780984.

15. Biniak, S., Świątkowski, A., Pakuła, M., Sankowska, M., Kuśmierek, K., \& Trykowski, G. (2013). Cyclic voltammetric and FTIR studies of powdered carbon electrodes in the electrosorption of 4-chlorophenols from aqueous electrolytes. Carbon 51, 301-312. DOI: http://dx.doi.org/10.1016/j.carbon.2012.08.057.
16. Aksu, Z. \& Yener. J. (1998). Investigation of the biosorption of phenol and monochlorinated phenols on the dried activated sludge. Proc. Biochem. 33(6), 649-655. DOI: 10.1016/S00329592(98)00029-6.

17. Aksu, Z. \& Yener, J. (2001). A comparative adsorption/ biosorption study of mono-chlorinated phenols onto various sorbents. Waste Manage. 21, 695-702. DOI: 10.1016/S0956$-053 X(01) 00006-X$.

18. Lin, S.H. \& Juang, R.S. (2009). Adsorption of phenol and its derivatives from water using synthetic resins and low-cost natural adsorbents: A review. J. Environ. Manage. 90, 1336-1349. DOI: 10.1016/j.jenvman.2008.09.003.

19. Aksu, Z. (2005). Application of biosorption for the removal of organic pollutants: a review. Proc. Biochem. 40, 997-1026. DOI: $10.1016 /$ j.procbio.2004.04.008.

20. Ahmaruzzaman, M. (2008). Adsorption of phenolic compounds on low-cost adsorbents: A review. Adv. Colloid Interf. Sci. 143, 48-67. DOI: 10.1016/j.cis.2008.07.002

21. Park, D., Yun, Y.S. \& Park, J.M. (2010). The past, present, and future trends of biosorption. Biotechnol. Bioproc. Eng. 15, 86-102. DOI/10.1007/s12257-009-0199-4.

22. Kumar, N.S., Subbaiah, M.V., Reddy, A.S. \& Krishnaiah, A. (2009). Biosorption of phenolic compounds from aqueous solutions onto chitosan-abrus precatorius blended beads. J. Chem. Technol. Biotechnol. 84, 972-981. DOI: 10.1002/jctb.2120.

23. Kumar, N.S. \& Min, K. (2011). Phenolic compounds biosorption onto Schizophyllum commune fungus: FTIR analysis, kinetics and adsorption isotherms modeling. Chem. Eng. J. 168, 562-571. DOI: 10.1016/j.cej.2011.01.023.

24. Radhika, M. \& Palanivelu, K. (2006). Adsorptive removal of chlorophenols from aqueous solution by low cost adsorbent-Kinetics and isotherm analysis. J. Hazard. Mater. B138, 116-124. DOI: 10.1016/j.jhazmat.2006.05.045.

25. Kurniawan, T.A., Waihung, L., Repo, E. \& Sillanpaa, M.E.T. (2010). Removal of 4-chlorophenol from contaminated water using coconut shell waste pretreated with chemical agents. J. Chem. Technol. Biotechnol. 85, 1616-1627. DOI: 10.1002/ jctb.2473.

26. Kazmi, M., Saleemi, A.R., Feroze, N., Yaqoob, A. \& Ahmad, S.W. (2013) Removal of phenol from wastewater using activated waste tea leaves. Pol. J. Chem. Tech. 15(2), 1-6. DOI: 10.2478/pjct-2013-0016.

27. Kuśmierek, K., Dąbek, L., Kamiński, W. \& Świątkowski, A. (2013). Evaluation of the usefulness of peat for removal of chlorophenols from water solutions. Ochr. Srod. 35(2), 51-55. [In polish].

28. Ferrero, F. (2007). Dye removal by low cost adsorbents: Hazelnut shells in comparison with wood sawdust. J. Hazard. Mater. 142, 144-152. DOI: 10.1016/j.jhazmat.2006.07.072.

29. Dogan, M., Abak, H. \& Alkan, M. (2008). Biosorption of methylene blue from aqueous solutions by hazelnut shells: equilibrium, parameters and isotherms. Water Air Soil Pollut. 192, 141-153. DOI: 10.1007/s11270-008-9641-z.

30. Altun, T. \& Pehlivan, E. (2007). Removal of copper(II) ions from aqueous solutions by walnut-, hazelnut- and almond-shells. Clean 35(6), 601-606. DOI: 10.1002/clen.200700046. 31. Altun, T. \& Pehlivan, E. (2008). Biosorption of chromiu$\mathrm{m}(\mathrm{VI})$ ion from aqueous solutions using walnut, hazelnut and almond shell. J. Hazard. Mater. 155, 378-384. DOI: 10.1016/j. jhazmat.2007.11.071.

32. Teixeira, S., Delerue-Matos, C. \& Santos, L. (2012). Removal of sulfamethoxazole from solution by raw and chemically treated walnut shells. Environ. Sci. Pollut. Res. 19, 3096-3106. DOI: $10.1007 / \mathrm{s} 11356-012-0853-9$.

33. Gala, A. \& Sanak-Rydlewska, S. (2012). A comparision of $\mathrm{Pb}^{2+}$ sorption from aqueous solutions on walnut shells and plum stones. Pol. J. Environ. Stud. 20(4), 877-883.

34. Gala, A. \& Sanak-Rydlewska, S. (2012). Use of walnut shells for removing $\mathrm{Cd}^{2+}$ ions from aqueous solutions. Przem. Chem. 91(4), 531-536. [In polish]. 
35. Ferro-Garcia, M.A., Rivera-Utrilla, J., Bautista-Toledo, I. \& Moreno-Castilla, C. (1998). Adsorption of humic substances on activated carbon from aqueous solutions and their effect on the removal of $\mathrm{Cr}(\mathrm{III})$ ions. Langmuir 14, 1880-1886.

36. Moreno-Castilla, C. (2004). Adsorption of organic molecules from aqueous solutions on carbon materials. Carbon 42, 83-94. DOI: 10.1016/j.carbon.2003.09.022.

37. Lagergren, S. (1898). Theorie der sogenannten adsorption geloester stoffe, Vetenskapsakad. Handl. 24, 1-39.

38. Ho, Y.S. \& McKay, G. (1999). Pseudo-second-order model for sorption processes. Process. Biochem. 34, 451-465. DOI: 10.1016/S0032-9592(98)00112-5.

39. Weber Jr., W. \& Morris, J. (1963). Kinetics of adsorption on carbon from solution. J. Sanit. Eng. Div. ASCE 18, 31-42. 40. Hameed, B.H. (2009). Spent tea leaves: A new non-conventional and low-cost adsorbent for removal of basic dye from aqueous solutions. J. Hazard. Mater. 161, 753-759. DOI: 10.1016/j.jhazmat.2008.04.019.

41. Lorenc-Grabowska, E. Gryglewicz, G. \& Diez, M.A. (2013). Kinetics and equilibrium study of phenol adsorption on nitrogen-enriched activated carbons. Fuel 114, 235-243. DOI: http:// dx.doi.org/10.1016/j.fuel.2012.11.056.

42. Giles, C.H., MacEwan, T.H., Nakhwa, S.N. \& Smith, D. (1960). Studies in adsorption. Part XI. A system of classification of solution adsorption isotherms, and its use in diagnosis of adsorption mechanisms and in measurement of specific surface areas of solids. J. Chem. Soc. 60, 3973-3393.

43. Freundlich, H.M.F. (1906). Über die adsorption in lösungen. Z. Phys. Chem. 57, 385-470.

44. Akcay, M. \& Akcay, G. (2004). The removal of phenolic compounds from aqueous solutions by organophilic bentonite. J. Hazard. Mater. B113, 189-193. DOI: 10.1016/j. jhazmat.2004.06.026.

45. Monsalvo, V.M., Mohedano, A.F. \& Rodriguez, J.J. (2012). Adsorption of 4-chlorophenol by inexpensive sewage sludge-based adsorbents. Chem. Eng. Res. Des. 90, 1807-1814. DOI: http://dx.doi.org/10.1016/j.cherd.2012.03.018.

46. An, F., Du, R., Wang, X., Wan, M., Dai, X. \& Gao, J. (2012). Adsorption of phenolic compounds from aqueous solution using salicylic acid type adsorbent. J. Hazard. Mater. 201-202, 74-81. DOI: 10.1016/j.jhazmat.2011.11.037.

47. Liu, Q.-S., Zheng, T., Wang, P., Jiang, J.P. \& Li, N. (2010). Adsorption isotherm, kinetic and mechanism studies of some substituted phenols on activated carbon fibers. Chem. Eng. J. 157, 348-356. DOI: 10.1016/j.cej.2009.11.013. 